Background Implementation of sentinel surveillance for monitoring sexually transmitted infections (VICITS) among female sex workers (FSW) in Honduras began in March 2006 in Tegucigalpa, San Pedro Sula and La Ceiba. VICITS is based on three pillars: STI diagnosis and treatment, condom use promotion and HIV testing and counselling.

Methods Patients at least 18 years of age who attended any of the three VICITS clinics in Honduras from 2006 to $2012(n=4730)$ were included. Bivariate analysis of an open cohort of FSW from three VICITS clinics was performed using Epi Info 7. We analysed trends in condom use by partner type comparing the first to the third visit. Results Reported condom use with clients in Tegucigalpa increased from $93.1 \%(\mathrm{~N}=627)$ in the first visit to $98.1 \%(\mathrm{~N}=322)$ in the third visit $(\mathrm{p}=0.001)$, in San Pedro Sula from $88.4 \%(\mathrm{~N}=980)$ to $97.4 \%(\mathrm{~N}=422)(\mathrm{p}<0.001)$ and in La Ceiba from $93.1(\mathrm{~N}=404)$ to $98.2 \%(\mathrm{~N}=114)(\mathrm{p}>0.001)$. Reported condom use with stable partners in the last 12 months was considerably lower, at $12.2 \%$ $(\mathrm{N}=98), 34.6 \%(\mathrm{~N}=130)$ and $26.7 \%(\mathrm{~N}=15)$ in 2012 . No statistically significant change in condom use at last sex with casual partners between the first and third visit was observed. Reported condom use at the third visit was $28.1 \%(\mathrm{~N}=57)$ in Tegucigalpa, $66.7 \%(\mathrm{~N}=33)$ in La Ceiba and $75.9 \%(\mathrm{~N}=108)$ in San Pedro Sula.

Conclusions We observed a significant increase in condom use with clients of FSW in San Pedro Sula and moderate increase in Tegucigalpa and in La Ceiba (not significantly). Condom use with casual and stable partners remains persistently low and should be the focus of behaviour change interventions to increase condom use with casual and stable partners, both during counselling session in VICITS clinics as well as NGO-based outreach activities.

\section{P3.407 CHLAMYDIA PREVALENCE AND CONDOM USE DURING 2012 AMONG FEMALE SEX WORKERS ATTENDING STI CLINICS IN HONDURAS}

doi:10.1136/sextrans-2013-051184.0859

${ }^{1} \mathbf{F}$ Tinajeros, ${ }^{1} \mathrm{~N}$ Artiles, ${ }^{1} \mathrm{~F}$ Flores, ${ }^{2} \mathrm{~S}$ Mendoza, ${ }^{3} \mathrm{~N}$ Farach. ${ }^{\top} T E P H I N E T$, Tegucigalpa, Honduras, ${ }^{2}$ Ministry of Health, Tegucigalpa, Honduras, ${ }^{3} \mathrm{CDC} / \mathrm{CAR}$, Tegucigalpa, Honduras

Background Evidence has shown that efforts targeted towards controlling STI to maintain lower prevalence rates among key populations slows the spread of the epidemic to the general population. The question is: What is Chlamydia prevalence in sex workers attending STI clinics by work venue? Implementation of the sentinel surveillance for STI among FSW in Honduras began in March 2006 in Tegucigalpa, San Pedro Sula and La Ceiba. VICITS is based on STI diagnosis/treatment, condom promotion and counselling.

Methods From 2006 to 2012 we collected information about STI and behaviour of female sex workers in clinical history and analyse with Epi Info 7 the characteristics of participants by time, place and person. A bivariate analysis of an open cohort from 2007 to 2012 was performed. We compared the Chlamydia prevalence by work venue (venue-based versus street-based) and calculate $\mathrm{p}$ value by $\mathrm{X}^{2}$ Results During 2012, 761 FSW attended: 205 in Tegucigalpa, 438 in San Pedro Sula and 118 in La Ceiba. Median age was 27 years with 6.4 years of formal education. Chlamydia prevalence stood at $11.6 \%(\mathrm{~N}=301)$ in San Pedro Sula, $4.2 \%(\mathrm{~N}=144)$ in Tegucigalpa and $4.1 \%(\mathrm{~N}=49)$ in La Ceiba. Condom use in last sex with client was reported at $97.8 \%(\mathrm{~N}=179)$ in Tegucigalpa, $97.5 \%(\mathrm{~N}=325)$ in San Pedro Sula and 98.9\% (N=93) in La Ceiba. In street-based FSW from San Pedro Sula, chlamydia decreased from $8.7 \%$ in 2007 to $3.6 \%$ in 2012 ( $p>0.001)$. However it increased in venue-based FSW from $7 \%$ in 2007 to $13.5 \%$ in 2012 ( $p>0.001$ )

Conclusions Reported condom use is high, yet Chlamydia prevalence remains elevated, especially in venue-based FSW in Pedro Sula. As $70 \%$ of FSW attending the clinic are venue-based, this increases overall prevalence results for that site but not statistically significantly.
Behavior change activities should be expanded, especially among venue-based FSW.

\section{P3.408 SEX WORK INVOLVEMENT PREDICTS POOR VIRAL LOAD SUPPRESSION AMONG PEOPLE WHO INJECT DRUGS IN A CANADIAN SETTING}

doi:10.1136/sextrans-2013-051184.0860

${ }^{1,2} \mathbf{L}$ Ti, ${ }^{1,3} \mathrm{M}$ Milloy, ${ }^{1,4} \mathrm{~K}$ Shannon, ${ }^{1,4} \mathrm{~T}$ Kerr, ${ }^{1} \mathrm{~A}$ Simo, ${ }^{1,4} \mathrm{~J}$ Montaner, ${ }^{1,4} \mathrm{E}$ Wood. ${ }^{1} B C$ Centre for Excellence in HIVIAIDS, Vancouver, BC, Canada; ${ }^{2}$ School of Population and Public Health, University of British Columbia, Vancouver, BC, Canada; ${ }^{3}$ Department of Family Practice, University of British Columbia, Vancouver, BC, Canada; ${ }^{4}$ Department of Medicine, University of British Columbia, Vancouver, BC, Canada

Introduction In addition to its role in HIV disease progression, recent studies have demonstrated the crucial function of plasma HIV-1 RNA viral load (pVL) on HIV transmission. However, there is limited empiric research on virologic outcomes among people who use illicit drugs (PWID) and are engaged in sex work. The main objective of this study was to investigate the relationship between sex work and pVL suppression among PWID in Vancouver, Canada. Methods Data were derived from the AIDS Care Cohort to evaluate Exposure to Survival Services (ACCESS), an ongoing prospective cohort of HIV-positive PWID linked to comprehensive clinical information in a setting of universal no-cost HIV care. Using generalised estimating equations (GEE), we studied the longitudinal relationship between sex work and pVL suppression, defined as $<500$ copies HIV RNA per millilitre. In addition, we tested whether adherence to antiretroviral therapy (ART) mediated the relationship between sex work involvement and pVL suppression.

Results Between May 1996 and May 2012, 608 ART-exposed participants were included in the study and completed 2458 personyears of observation. In a multivariate model adjusted for possible confounders, sex work was independently associated with poorer odds of pVL suppression (Adjusted Odds Ratio $[\mathrm{AOR}]=0.65 ; 95 \%$ confidence interval [CI]: $0.46-0.92)$. Using a validated measure of pharmacy refill, we found that adherence mediated this relationship (Sobel test statistic $=4.44, p<0.01$ ).

Conclusions In this study, we found that PWID were less likely to experience virologic control during periods of engagement in sex work, a relationship mediated by adherence. In light of these findings, interventions to improve adherence to ART among individuals engaged in sex work are urgently needed to help produce the maximum HIV treatment and prevention benefit of ART among PWID.

\section{P3.409* SEXUAL HEALTH IN THE ADULT FILM INDUSTRY (AFI): ENVIRONMENTAL BARRIERS AND FACILITATORS OF SEXUALLY TRANSMITTED INFECTION (STI) TRANSMISSION}

doi:10.1136/sextrans-2013-051184.0861

'P. Lilleston, 'E. Mead, 'D. Cernigliaro, ${ }^{2} \mathrm{~S}$. G. Sherman.'Department of Health Behavior, and Society, Johns Hopkins Bloomberg School of Public Health, Baltimore, MD, United States, 2Department of Epidemiology, Johns Hopkins Bloomberg School of Public Health, Baltimore, MD, United States.

Background Adult film is a legal form of sex work in the U.S. that places performers at heightened risk of acquiring an STI. However, very little public health research exists on the environmental factors that influence STI transmission in the AFI.

Methods We explored the nature of the AFI's STI risk environment in semi-structured in-depth interviews $(\mathrm{N}=28)$ with performers, producers, directors and key informants from December 2012 through February 2013. Recruitment was conducted via purposive and snowball sampling. Interviews took place in-person and via phone. Data were analysed using an inductive approach in Atlas-ti. Results Participants described facilitators and barriers to STI transmission at the policy, economic, and social levels. On the 
policy level, mandatory STI testing and exclusion from work based on a positive test were perceived as largely effective in preventing STIs. However, some participants believed the required panel missed prevalent STIs (e.g. herpes) and modes of transmission (e.g. oral, anal). Unless required by the production company, condom use was rare, and no formal mechanisms existed for notifying partners of an STI. On the economic level, performers' earnings increased with number of sexual partners and riskier sexual acts. Most performers had no health insurance, paying out-of-pocket for STI testing and treatment. Due to the AFI's unsteady payment structure, many performers engaged in sexual escorting to supplement income. On the social level, seasoned performers felt empowered to advocate for their preferences regarding sexual practises and partners on set. However, fear of losing work, compounded by competition among performers, could put newer performers at greater risk for an STI. Although most performers preferred not to use condoms on set, participants described implicit and explicit pressure from producers and directors towards non-condom use.

Conclusion This study highlights important characteristics of the AFI environment that could be targeted for STI prevention interventions.

\section{P3.410 LINK WORKER SCHEME-AN EFFECTIVE RURAL INTERVENTION TO REDUCE THE VULNERABILITY OF CONTRACTING HIV AMONG RURAL SEX WORKERS}

doi:10.1136/sextrans-2013-051184.0862

\section{A Mallick, R Das, A Ghosh. Child In Need Institute, Kolkata, India}

Background Link Worker Scheme, a rural intervention model aims to reach out to the High Risk Groups and vulnerable men and women in rural areas with information, knowledge, skills on STI/ HIV prevention and risk reduction. In the district of Burdwan the programme has reached out to 2629 sex workers to reduce their vulnerability of contracting HIV infection. They are being reached out by the link workers selected from the community itself and they are linked up with the STI clinics and also with government supported Integrated counselling and testing centres for availing services.

Method Since 2009 the programme is being rolled out in 100 villages targeting 2629 rural sex workers. They are made empowered with need based knowledge and skills for reducing their own vulnerability of contracting HIV infection. Side by side various midmedia and awareness programmes are conducted addressing the preventive and vulnerability reduction issues. Condoms are being made available to the sex workers through various channels which are easily accessible to them. After thorough counselling 2080 sex workers have undergone HIV testing at different government supported integrated counselling and testing centres (ICTC). Regular follow-ups are being done by the link workers with support from village level government health service providers and other community stakeholders.

Result From September 2009 to January 2013, 2080 sex workers have undergone HIV testing out of which only 8 ( $0.4 \%)$ have been found HIV positive.

Conclusion Through the programme activities rural sex workers have been reached out effectively by the community based dedicated link workers and the sex workers have realised their own vulnerability and opted for practising safe sexual behaviour in order to reduce their vulnerability of being contracted by the virus. The outcome of the programme has shown a positive response towards achieving the goal of the programme.

\section{P3.411 FACTORS AFFECTING UTILISATION OF STI/HIV CLINICS AMONG SEX WORKERS IN BENIN,}

doi:10.1136/sextrans-2013-051184.0863
'G Batona, ${ }^{2}$ Sémini, 'M Gagnon, ${ }^{3} \mathrm{~F}$ Guedou, 1,4M Alary. 'Université Laval, Québec, OC, Canada; ' World Bank, Washington, WA, United States; ${ }^{3}$ Dispensaire IST, Cotonou, Benin; ${ }^{4} \mathrm{CHU}$ de Québec, Québec, OC, Canada

Background In Benin, HIV/STI clinical and prevention services (based on community mobilisation activities) for female sex worker (FSWs) were extended throughout the country. However, the attendance of clinical services remains very low. Most of the FSW-dedicated clinics are not functional.

Objective This study explores factors related to low functionality and sub-optimal attendance of clinical services by FSWs.

Methods Individual interviews and/or focus groups were conducted with 35 FSWs, 50 health care providers, 70 stakeholders from NGOs and 18 departmental heads of the National AIDS Program in 9 of the 12 regions of the country. Interview guides were developed using a conceptual framework describing actors, implications and issues of implementation activities. Direct observations in the field and analysis of activity reports were also conducted. Data from various sources were triangulated and validated with stakeholders.

Results Several factors have undermined regular STI services utilisation by FSW, encompassing: (i) incomplete and insufficient package of services, with lack of integration of programme components, irregular and insufficient supervision, recurrent shortages of STI drugs and supplies; (ii) limited involvement of FSWs in the programme design, implementation and service organisation; (iii) police repression resulting in dispersion of FSWs, lack of empowerment activities (structural factors); (iv) fear of stigma, little motivation of some health provider to respond to FSWs needs; (v) dysfunctional referral between community level work and STI clinics. In addition poor planning that does not take into account local needs (size, diversification of sex work typologies) also contributes to the non-functionality of the FSW-dedicated clinical services.

Conclusion The results of this study suggest that innovative service delivery models that maximise the synergy between community level work, and uptake of health services need to be designed, implemented and evaluated. Clinical and community level work should also be complemented by appropriate structural interventions.

\section{P3.412 PERSONAL EXPERIENCE OF VIOLENCE AS POTENTIAL RISK FACTOR OF HIV/STI AMONG FSWS IN UKRAINE}

doi:10.1136/sextrans-2013-051184.0864

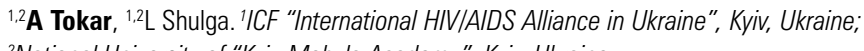
2National University of "Kyiv-Mohyla Academy", Kyiv, Ukraine

Background In Ukraine where the main road of HIV transmission in Ukraine is sexual, female sex workers are considered to have increased risk of HIV and STI infections. Moreover, FSWs suffer from different kinds of violence such as: economic, physical and psychological. The goal of our research was to define if personal experience of violence is associated with risk of HIV/STI infections. Methods Secondary data analysis was performed on the dataset of bio-behavioural survey with 5023 respondents (FSWs) conducted in 2011 by the ICF "HIV/AIDS Alliance in Ukraine". RDS and TLS sampling methodology were applied, only females were recruited. The study was approved by Ethical Review Board of Ukrainian Sociological Association and Institute of epidemiology and infectious diseases named after L. V. Gromashevskyi.

To reveal relationships between HIV/STI rapid tests results and personal experience of violence of FSWs binary logistic regression analysis was provided in SPSS 15.0.

Results About $55 \%$ of respondents were aged 20-30 years old, $52 \%$ - completed secondary, vocational school and obtained not full high education, $64 \%$ - were unmarried and did not live together with sexual partner. Personal experienced of violence were positively 